\title{
Gene therapy researcher under fire over controversial cancer trials
}

Washington. A scientific oversight panel at the US National Institutes of Health (NIH) has withheld funding for a contract supporting the work of Steven Rosenberg, an NIH cancer researcher, after criticizing Rosenberg for continuing to conduct controversial gene therapy trials despite evidence that crucial elements have failed to work as hoped.

Rosenberg has often been a controversial figure at NIH, both for his aggressive approach to cancer therapy and his tendency to get more press for the initiation of his trials than for their results. Now, for the first time, one of NIH's own advisory bodies has questioned the science and propriety of his trials.

In an unusually critical attack, the board of scientific counsellors of the National Cancer Institute's Division of Cancer Treatment has raised questions about several central aspects of Rosenberg's trials in which tumour-infiltrating lymphocyte (TIL) cells are extracted from cancer patients, grown in the laboratory, and transfected with the gene for tumour necrosis factor (TNF), a protein that interferes with a tumour's blood supply. The TNF-producing TIL cells are injected back into the patient, where they are expected to home in on tumours, infuse them with TNF and kill them.

But several important aspects of the TNF-TIL experiments have failed to work as hoped in the two years since Rosenberg first gained approval to start his clinical trials with modified TIL cells. He has had continuing problems in getting the geneti-

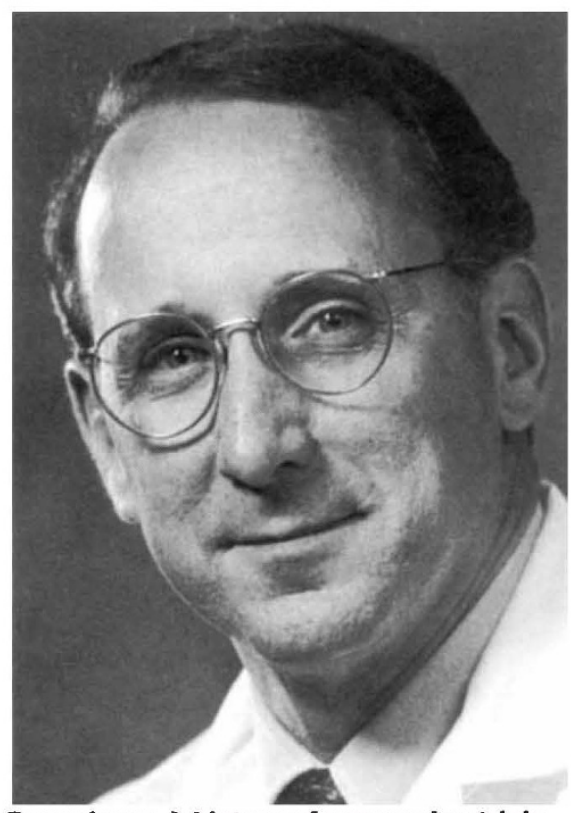

Rosenberg: A history of aggressive trials

cally modified TIL cells to express TNF at levels high enough to affect the tumours. And, although his earlier experiments with unmodified TIL cells showed that they usually collect at tumours as expected, the TNF TILs do not appear to be performing as well. Something about the insertion of the TNF gene into the TIL cells may be interfering with their homing ability. As a result, many appear to end up in the liver and elsewhere in the body, where the TNF could be toxic were it to be expressed.

At a meeting on 20 October, the board of scientific counsellors openly challenged Rosenberg, using the closest weapon at hand: a \$3.9 million, three-year contract to pay an a independent laboratory to grow TIL cells. Rosenberg contends that the trials have shown enough success to be continued and have yielded significant insights that may lead to improved gene therapy approaches in the next generation of trials. Nevertheless, the board voted not to renew the contract until Rosenberg answered a list of questions on his progress.

Coming just as Rosenberg is preparing to launch a major new clinical trial using a new vector to put the TNF genes into TIL cells, the committee's decision to freeze funding for the TIL production could be a significant blow. Even if Rosenberg can satisfy the board, the contract will not come up for another vote until the board's next meeting in February.

Few of these concerns are new; indeed many of the same questions came up during the initial approval hearings by NIH's Recombinant DNA Advisory Panel (RAC) in July 1990. At the time, Rosenberg had little animal data to support his protocol when he presented it to the RAC; indeed,

\section{Frustration brought panel to showdown}

Washington. By all accounts, the showdown between Steven Rosenberg and the Division of Cancer Treatment board of scientific counsellors has been building for months as board members became increasingly concerned about what some felt were questionable trials with insufficient oversight.

When the board visited Rosenberg's laboratory in February, members raised a series of concerns about his gene therapy trial, including whether the genetically modified cells were expressing as much of a tumour-killing protein as projected and whether the cells were localizing at tumour sites. Yet at their 30 October meeting, they were no closer to getting the answers they wanted, and the frustration was starting to show.

"There was a lack of preclinical data for virtually every one of the issues that [Rosenberg] was propos[ing], and it would help if Steve provided the preclinical data to us. What we got instead were a series of preprints, none of which really answers those questions", complained Philip Greenberg, a University of Washington oncologist who is a member of the board. "His response to the site visit was not adequate."

The board has also become concerned about Rosenberg's tendency to continue problematic trials until explicitly told to stop. Ralph Weichselbaum, a University of Chicago oncologist, noted that at the February 1992 site visit, "there were a series of - I don't want to be misquoted - not particularly successful trials [comparing high-dose interleukin-2 and interleukin-2 plus lymphokine-activated killer cells] that he was going to continue". The board recommended that he stop the trials, and Rosenberg eventually halted them in August. But Weichselbaum suggested that the experience indicated that some additional "constructive oversight" of Rosenberg's trials is in order.

Loretta Itri, another panel member, summed up the panel's frustration: "It seems to me that there have been straightforward questions asked. I am very disturbed that two meetings after the site visit we are still debating [them]."

As Greenberg put it, although the members generally support Rosenberg's work, "there [is] a difference between supporting the advance of science as opposed to supporting proceeding rapidly to clinical trials". Without clear evidence that Rosenberg's trials are working, the board apparently felt it had no choice but to assume the worst. 